\title{
Mitteilungen
}

\section{Speyerer Vergaberechtstage 2013}

Wie in jedem Jahr werden auch die Speyerer Vergaberechtstage 2013 am 26. und 27. September 2013 in zahlreichen Beiträgen aktuelle Fragen des Vergaberechts analysieren und diskutieren. Die Veranstaltung richtet sich in erster Linie an alle mit der praktischen Anwendung des Vergaberechts Befassten.

Als Themen sind u. a. geplant:

- Die Weiterentwicklung des Europäischen Vergaberechts

- Das Richtlinienpaket der Kommission: Was wird sich ändern?

- Die schrittweise Weiterentwicklung des Agreement on Government Procurement

- EU-Verordnungsvorschlag zum Marktzugang aus Drittstaaten zu EU-Beschaffungsmärkten

- Zuwendungen und Vergaberecht

- Vorgehen bei Vertragsänderungen - unter Berücksichtigung der neuen EU-Richtlinien

- VOF und Wettbewerbe

- Die Pflicht zur Losaufteilung: Von der Norm zur Praxis

- Die Vergabe von Busdienstleistungen im öffentlichen Personennahverkehr nach der VO (EG) 1370/2007, dem GWB oder dem PBefG?

- Nachhaltige Beschaffung in der Vergabepraxis

- Maßgeblicher Zeitpunkt der Rechtmäßigkeit der Vergabeentscheidung(en)?

- Materielle Vorgaben für ein Vergabeverwaltungsrecht

- Zulassung von Recyclingmaterialien bei öffentlichen Ausschreibungen

Detailliertes Programm, Auskünfte und Anmeldung: Univ.-Prof. Dr. Jan Ziekow, Deutsche Universität für Verwaltungswissenschaften Speyer, Postfach 1409, 67324 Speyer, Tel. 06232 / 654-360, Fax -421. e-mail ziekow@uni-speyer.de. Internet: www.uni-speyer.de 